\title{
Choices of Research Methodologies on Climate Change Adaptation Especially Focusing on Agriculture Sector: A Systematic Review
}

\author{
Shree Kumar Maharjan ${ }^{1} \&$ Keshav Lall Maharjan ${ }^{1}$ \\ ${ }^{1}$ Graduate School of International Development and Cooperation, Hiroshima University, 1-5-1 Kagamiyama, \\ Higashi-Hiroshima 739-8529, Japan \\ Correspondence: Shree Kumar Maharjan, Graduate School of International Development and Cooperation, \\ Hiroshima University, 1-5-1 Kagamiyama, Higashi-Hiroshima 739-8529, Japan. Tel: 81-806-269-8826. E-mail: \\ smilingsiri@gmail.com
}

Received: June 5, 2018 Accepted: June 22, 2018 Online Published: September 17, 2018

doi:10.5539/sar.v7n4p91

URL: https://doi.org/10.5539/sar.v7n4p91

\begin{abstract}
A rapid increase in climate researches by applying diverse methodologies and approaches in recent decades. These researches have directly or indirectly contributed in better understanding of climate issues, risks and vulnerabilities. It has improved awareness and capacities of the public and communities to adapt to the vulnerabilities and impacts. It, further, contributes in formulation of climate policies and plans to address climate risks and vulnerabilities at the local and national levels. Appropriate methodologies lead to better results in the researches. This paper has applied systematic review of the published papers $(2010-2017)$ to understand the general and specific research methodologies in climate discourse especially in Web of Science (WS), Springer Link (SL) and Science Direct (SD). Altogether, 37 journal papers (10 WS, 13 SL and 14 SD) were selected for the detail analysis based on the assessment of abstracts, which was mainly concentrated on research methodologies specializing in agriculture. In the process, the authors have analyzed the contents, research methodologies, data analysis, and geographical coverages. The analysis, further, concentrated on the scope and limitations of the research methodologies used. Wide-ranging research methodologies are found that are applied by the researchers in the climate change discourse. Some researchers have applied general research methodologies whereas others have used specific research methodologies and model analysis. Furthermore, it is comprehended that the combination of research methodologies and approaches through focus group discussion together with household survey and model analysis is the effective way for the research by using quantitative and qualitative data.
\end{abstract}

Keywords: adaptation, agriculture, climate change, participatory approaches, research methodologies

\section{Introduction}

The researches on climate change discourse are rapidly increasing in recent years because of increased climatic risks, vulnerabilities and impacts in all sectors at all levels (Lwasa, 2014). These researches and assessments are focused at different levels and scales (from the global to the national and also to the local level) and sectors (such as agriculture, forestry, health and medicine, water, education etc.). Diverse methodologies have been applied in the researches and assessments that directly or indirectly contribute to the policy, awareness and identifying key issues relating to climate change and environment. Different research approaches (both qualitative and quantitative), frameworks, methodologies and tools/models have been applied to assess and analyze the climatic risks, vulnerabilities, impacts and also adaptations based on specific research issues and focuses (UNFCCC, 2004; Winkel et al., 2013). Many of such researches have emphasized on adaptation to address the issues of climate change (Locatelli et al., 2008). Berrange-Ford et al., (2015) further emphasized on importance of comprehensive syntheses of existing research methods and tools to evaluate process on adaptation and climate policies.

As defined by Intergovernmental Panel on Climate Change (IPCC), vulnerability is the degree of susceptibility of an environmental or social system to cope with adverse effects of climate change, variabilities and extremes. It requires integrated assessment across the range of disciplinary spheres and scales with assessment tools and frameworks (Antwi-Agyei et al., (2012). Mostly top-down or scenario driven researches and approaches are prominent as compared to bottom up or vulnerability driven approaches, which is also taking momentum in 
climate change discourse in recent years (Locatelli et al., 2008). It is more effective to combine top-down and bottom up approaches with scientific data, information and local knowledge, practices for detail assessment of the entire process. Devkota (2014) emphasized on the importance of scientific knowledge of changing climate as well as the perception, knowledge and practices of local people. Most of the researches are concentrated on assessments of the climatic risks, vulnerabilities and adaptations to address the short and long-term impacts. Furthermore, the researches on the adaptive capacity, institutional capacities, climate policies, research methodologies and approaches are quite common concentrating at the different levels and sectors (Lockwood et al., 2015).

Appropriate methodologies and tools are the key for the success of any research. These researches, either at the community level or at the national level, use diverse methodologies, which provide the opportunities in sharing of knowledge, experiences and dialogues among the communities, researchers and other stakeholders based on set of guiding questions for analysis of data and information at different levels. Basically, these guiding questions help to examine the factors at the multiple levels using a variety of tools to gather information through a participatory process and collaborative learning. These researches contribute in designing effective climate change adaptation as well as integrating climate adaptation into livelihoods and natural resource management and overall development. This paper aims to review and analyze the research methodologies including participatory approaches and statistical/econometric models to guide the researches on climate change adaptation in agriculture in Nepal. It further analyzes the scope and limitations of these methodologies from academic point of view and unveils the research methodologies and tools for the research in adaptation in agriculture based on the research issues and questions.

\section{Methodological Framework}

The specific research framework is planned for this paper focusing on the methodologies commonly used in climate change researches mainly based on the papers published in Web of Science (WS), Springer Link (SL) and Science Direct (SD). The process ultimately help the fellow researchers to select the appropriate methodologies in the climate change researches with their specific research objectives and focuses. The specific research objectives and focuses could be related to climate change policies at the national and local level or assessment and analysis of climate risks, vulnerabilities and adaptation initiatives/interventions including needs and priorities of the communities at local level. The literature review, defining the research theme and inclusion/exclusion criteria are the initial steps of the systematic review followed by the systematic review of the published papers based on titles, contents and abstracts that leads to evaluation and analysis of selected papers and results interpretation and discussion (Figure 1).

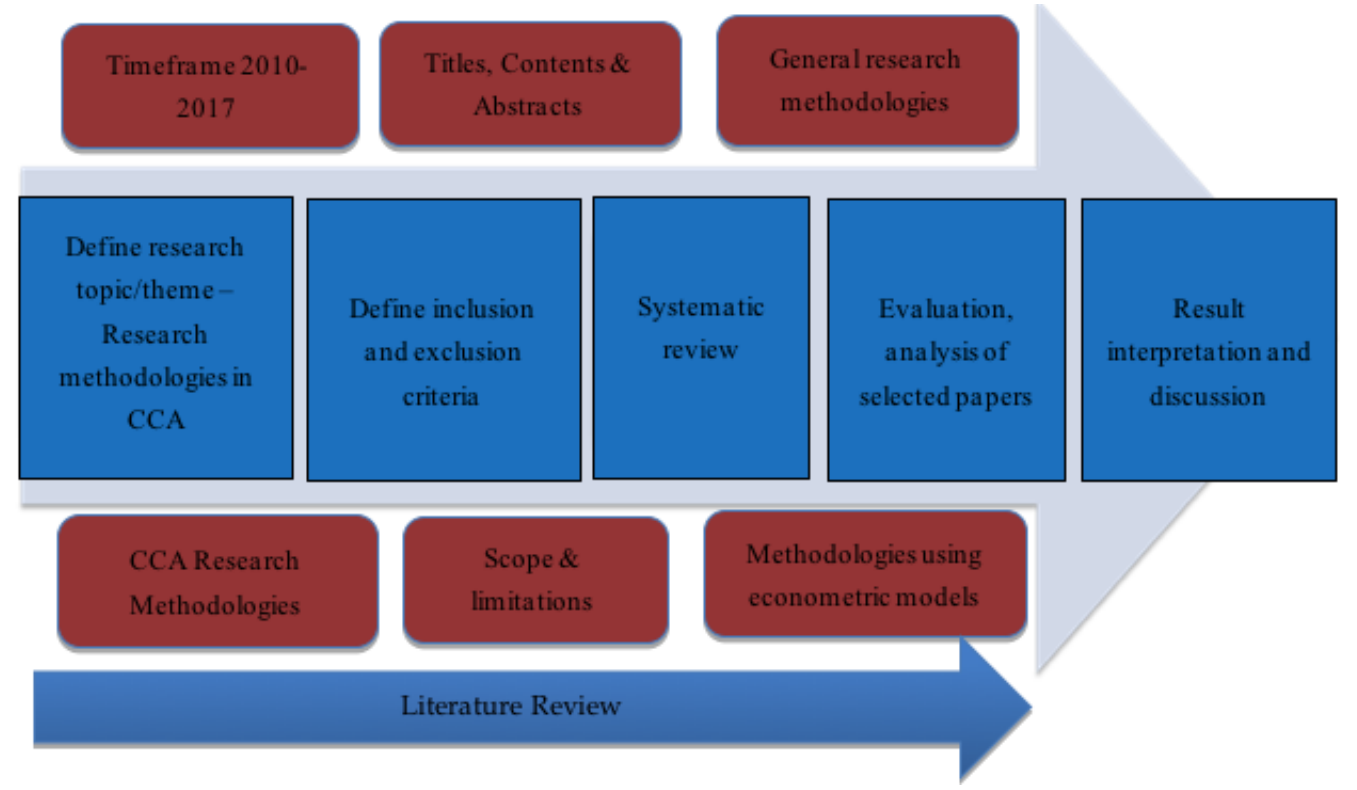

Figure 1. Methodological framework (Author's own creation) 


\section{Research Methodology}

This study is based on the systematic review and assessment of the research methodologies particularly concentrating on climate change adaptation in agriculture in the published papers in Web of Science (WS), Springer Link (SL) and Science Direct (SD). The open accessed research papers were searched specifically in the WS, SL and SD respectively for systematic review. Prior to search the papers in the databases, the inclusion and exclusion criteria were defined considering the research focus and interest (Table 1). These databases were chosen based on the popularity among the researchers and practitioners for the research on multiple issues and themes. The keywords "Research methodologies on climate change adaptation in agriculture" were used for the search and access the relevant papers in the selected database. The inclusion criteria for systematic search and review of the papers on these databases were open accessed journal papers in English on research methodologies concentrated in climate change adaptation in agriculture from the period of 2010 to 2017.

Table 1. The inclusion and exclusion criteria for systematic review of the papers

\begin{tabular}{lll}
\hline \multicolumn{1}{c}{ Inclusion Criteria } & \multicolumn{1}{c}{ Exclusion Criteria } \\
\hline - & Research methodologies in climate change adaptation & Papers related to \\
(CCA) in agriculture & - & Mitigation \\
- Open access journal papers published in Science Direct & - & Fisheries and winery, viticulture \\
(SD), Springer Link (SL) and Web of Science (WS) & Energy and livestock \\
- Original research papers & - Ecosystem services \\
- Papers in English Language & - Water reservoirs \\
- Published in between 2010-2017 & - Rural transportation \\
& - & Review papers, book chapters and short \\
& & communications are not included \\
\hline
\end{tabular}

The total numbers of papers found in the first search were 58, 544, and 562 in the WS, SL and SD respectively based on the inclusion criteria. The second search was more concentrated to climate change in agriculture within the selected papers, which reduced the number of papers to 41, 269 and 134 respectively. However, the papers related to mitigation, fisheries, winery, viticulture, energy and livestock, ecosystem services, water reservoirs and rural transportation were also found within the list. Thus, those papers were excluded from the list by reviewing the title of the papers. The review papers, book chapters, short communications are also excluded as well. Some of the review papers, abstracts and conference papers were also found during the detail review of the titles, thus discarded from the list as well. By clearance of the papers based on exclusion criteria, the number of papers has been reduced to 15, 30, and 25 respectively (Table 2). The abstracts of these papers were reviewed to finalize the total number of papers for the detail systematic review and assessment of research methodologies on climate change adaptation in agriculture.

Table 2. Number of papers selected through the process of systematic review

\begin{tabular}{lllll}
\hline $\begin{array}{l}\text { Search } \\
\text { Databases }\end{array}$ & $\begin{array}{l}\text { First search with keywords } \\
\text { research methodologies } \\
\text { CCA in agriculture }\end{array}$ & $\begin{array}{l}\text { Second search with the } \\
\text { keywords climate change } \\
\text { adaptation in agriculture }\end{array}$ & $\begin{array}{l}\text { Third } \\
\text { with exclusion } \\
\text { criteria }\end{array}$ & $\begin{array}{l}\text { Final Selection } \\
\text { based } \\
\text { Abstracts }\end{array}$ \\
\hline $\begin{array}{l}\text { Web of } \\
\text { Science (WS) }\end{array}$ & 58 & 41 & 15 & 10 \\
$\begin{array}{l}\text { Springer Link } \\
\text { (SL) }\end{array}$ & 544 & 269 & 30 & 13 \\
$\begin{array}{l}\text { Science } \\
\text { Direct (SD) } \\
\text { Total }\end{array}$ & 562 & 134 & 25 & 14 \\
\hline
\end{tabular}

Finally, 37 journal papers (10 from WS, 13 from SL and 14 from SD respectively) were selected for detail review and analysis based on the assessment of the abstracts, which was mainly concentrated on research methodologies specializing climate change adaptation in agriculture. In the process, the authors have analyzed the contents, research methodologies and tools adopted, data analysis, geographical coverages in the selected papers. The analysis further concentrated on the scope and limitations of the research methodologies in the research on climate change adaptation in agriculture. 


\section{Key Results and Discussion}

\subsection{Quantitative vs Qualitative Researches}

The study found application of different research methods and tools in climate change in agriculture specific to the research focus and research interest. The results have shown that the researchers are highly motivated to quantitative data and model analysis than the qualitative analysis. Among the total research papers identified, $48.64 \%$ researches have focused on quantitative analysis. Only $27.02 \%$ have concentrated on qualitative research and rest $(24.32 \%)$ have concerted on combination of quantitative and qualitative research. In terms of geographical coverage, $56.75 \%$ papers were concentrated at the national level whereas $24.32 \%$ were focused at the regional and sub-regional levels. Diverse methodologies, methods, tools and models have been used to analyze the climate data, trend and information for both quantitative and qualitative researches. It is complicated and challenging to understand and exchange the coherent arguments particularly on research methods used in climate change adaptation research. Hinkel and Bisaro (2015) also supported the complex and complications of the climate change researches with the multiple research methods and tools being used by the researchers. The arguments and debates on climate researches are centered on issues of quantitative versus qualitative data and research over the years. Some argued quantitative research is better and more scientific than qualitative research, whereas others believed that quantitative and qualitative researches are just different methodologies - neither is better than each other (Dawson, 2009).

Based on the research objectives and focuses, the researchers have focused different methodologies. For instance, some of the researches emphasized on general trend analysis, focus group discussion (FGD), household (HH) survey, assessment of seasonal variation, vulnerability and adaptive capacity assessment (VACA). Likewise, other researchers have applied the network analysis and farming system approach, spatial distribution, participatory and rapid rural appraisal tools. Some of the researchers have applied specific methodologies such as economic and bio-climate models, hydro-economic modeling, agriculture production systems simulation, land use allocation model, econometric and regression analysis (multinomial logit, ordinary least square (OLS) method, binary logistic regression model). Furthermore, other researches have concentrated on specific models and software for analysis such as simpson index of diversification \& cropping intensity index, vegetation interface processes (VIP) based ecosystem model and weather research forecasting, decision support system for agro-technology (DSSAT) software, stochastic rainfall model combined with weather generator etc. There are some researches that have focused on agro-ecological zones, multi-criteria scoring methods, decision making models, and marginal rate of return (MRR) and willingness to pay, cost-benefit analysis (CBA), principal component analysis (PCA), expert opinion survey (EOS). Detail of the these research methods is available in Annex 1.

Mostly qualitative researches have applied comparatively general methodologies, conceptualization, case studies and integrated approaches whereas quantitative researches have applied specific tools and software such as STATISTICA, STATA and decision support software. Wenkel et al. (2013) emphasized on the progresses in the field of climate discourse with the use of geographical information systems (GIS), computer science, climate modeling and new data acquisition technologies. Mostly these simulations and modeling require up-to-date scientific knowledge and climate information from regional and global climate scenarios. However, these scientific models and analyses are complex and difficult for general public and communities to understand. The communities have own understanding and experiences of changing climate based on local knowledge and practices. Thus, combination of scientific and local knowledge on climate change minimizes gaps in model analyses and perceptions and experiences of the communities. Some of the researchers (such as Devkota 2014; Lockwood et al., 2015) have emphasized on the combination of local knowledge with scientific data to build and enhance the people's understanding on climate risks and adaptation strategies.

\subsection{Scope, Limitations and Gaps}

Each research methodology focuses on specific tools, procedures and combination of tools/procedures considering the research focus, interest and questions as well as the issues, available resources, time and sectors. Each of these research methodologies has its specific scope and limitations. Dawson (2009) also agreed on specific strengths and weaknesses of each methodology. Many researchers apply the methodologies for the participatory action research and analysis, especially in the field of natural sciences such as agriculture, forestry, biodiversity mainly at local/community level (Ahmed et al., 2014 \& Saccheli et al., 2016). IUCN, IISD, SEI \& Inter-cooperation (2007) and CARE (2009) also emphasized on participatory action research and analysis by developing the tools such as Community based Risk Screening - Adaptation and Livelihoods Tool (CRiSTAL) and Climate Vulnerability and Capacity Assessment (CVCA), respectively. Whereas, many other agencies such 
as Livelihood Forestry Programme (LFP) (2010) with the support of UKaid also developed and implemented participatory tools such as vulnerability matrices, timeline, hazard mapping among others for understanding and documenting the risks, vulnerabilities and implications of climate change in the peoples' livelihoods.

For academic research, several other tools and computer-based models have been applied by the researchers to understand and predict the climate systems and its behaviors at the global to the national and also at the local levels such as general circulation models including statistical models. Mostly these models incorporate the statistical software that analyzes the atmosphere and ocean circulations to address the climate questions and assumptions. Many researchers use computer-based models of climate system to better understand the future climate issues and projections. They also use range of scenarios using various assumptions based on future economic, social, technological and environmental conditions (EPA, 2016). It also focuses on frameworks for analyzing vulnerability and capacity to adapt at the community, households and individual level.

The gaps between research on climate change adaptation and policy still exist including the gaps in building capacities on climate forecasting, risk assessment, adaptive capacities of the farmers even conducting research on adaptation to deal with harsh climate (Ngeve et al., 2014). Sterrett (2011) identified the gaps on additional information and statistical analysis related to climate and hydro-geological changes in the South Asian region. She further reported the necessity of better communication between decision makers and scientific community. Hinkel and Bisaro (2015) argued on complication of climate change research because of diverse analytical methods applied from natural and social sciences by using abstract and ambiguous terms such as vulnerability and adaptive capacity without considering wider array of social science. There are quite a large number of research papers on climate change adaptation with use of diverse research methodologies. These researches are multidimensional and multi-scalar in nature with integrated tools for analysis of climate change impacts and adaptation (Esteve et al., 2015).

4.3 Discussion on Appropriate Research Methodologies for Climate Change Adaptation in Agriculture: A Case in Nepalese Context

Climate change impacts vary spatially and temporarily. In Nepalese context, the climate change impacts vary with the altitudinal, geographical and climatic variations. Further investigations are required to understand the complexity of climate change through detailed assessments (Antwi-Agyei et al., 2012). Since diverse research methodologies, approaches and tools are available, it is possible to apply appropriate research methodologies in the climate change researches even in Nepalese context. However, the reliable climatic data and data sources of multiple years at least for 30 years are crucial in the research, which is difficult in Nepalese context due to limited meteorological stations and geographical and climatic variations in the country. Karki et al. (2009) also affirmed that the researchers in Nepal have to still rely on literature review and scattered climatic information due to lack of long term high quality data for reliable analysis and predictions of climate change. The additional time, efforts, investments and capacities are required to gather and analyze climatic data because of challenge of extreme topography, thus, necessary to choose the appropriate and comprehensive methodology or approach for the adaptation research in Nepal. Not a single method or model has all the answers relating to climate change research. Thus, it is highly recommended to use different approaches and methodologies that complement each other (Sterrett 2011).

Climate change impacts are increasing over the years, which indicated climate crisis is real that needs urgent attention, short-term and long-term adaptation through joint, concerted efforts and interventions (Karki et al., 2009). Numbers of researches conducted by researchers and development agencies have also contributed in understanding and minimizing the climate crisis and impacts. It is found the specific research methodologies and/or combinations of methodologies are applied in climate change researches. Both qualitative and quantitative data and methods are utilized in these researches with specific research issues, problems and purposes. IUCN (2015) has emphasized on the combination of qualitative and quantitative methods in climate change research to understand and gather reliable data \& information. Berrange-Ford et al. (2015) has also given importance on comprehensive research methods and tools in climate change adaptation and policy research.

Review of the literature and state of climate change adaptation policies and practices in agriculture is crucial to understand prior to plan for the research. Systematic review is a newly emerged review method in climate change discourse by defining research questions, inclusion and exclusion criteria including in depth review and analysis of the content and context in the research and literature. Berrang-Ford et al. (2015) and Sud et al. (2015) has also emphasized on research syntheses of climate adaptation focusing on review of adaptation policies and practices and frameworks. The formal systematic review was started in health sciences, but widely adapted in other sectors including climate change adaptation (Berrang-Ford et al., 2015). It follows the combination of 
quantitative and qualitative analyses and complex iterative literature searches. Additionally, forward and backward citation tracking, snowballing method, personal communication and review of grey literatures will be integrated into the search methods.

Assessment of vulnerabilities, CC impacts and adaptation in agriculture has significant importance in climate change research in Nepal. National and regional scale multi-indicator vulnerability assessments are vital in assessing vulnerability across a large area (Antwi-Agyei et al., 2012). The IPCC third Assessment Report has defined CC impacts, vulnerability and adaptation assessment (UNFCCC, 2004). Vulnerability is associated with natural hazards like flood, droughts and social hazards like poverty etc. It is a function of the character, magnitude and rate of climate variation to which a system is exposed, its sensitivity and its adaptive capacity. The quantitative assessment of vulnerability is usually carried out by constructing a 'vulnerability index' that depends on several set of indicators in a sector and also in a region. Furthermore, the vulnerability also depends on frequency of occurrence of extreme events such as flood, drought and landslide in the region. Basically, it is a numerical scale calculated from a set of variables selected by the researcher for the regions/districts, used to compare with one another or with some reference. Participatory approaches such as hazard mapping, seasonal calendar, historical timeline and vulnerability matrix are important in the community through focus group discussions. These assessments support in understanding the community, locality, climate change impacts, vulnerabilities, and adaptation strategies.

Sterrett (2011) also emphasized on these analytical tools for better understanding the context including secondary research, institutional mapping, policy analysis and additional participatory tools. It is also important to quantify and analyse the direct and indirect cost associated with adaptation (UNFCCC 2011). Cost benefit analysis (CBA) is an established economic tool for determining the economic efficiency of adaptation/development interventions (Mechler \& The Risk to Resilience Study Team, 2008). The CBA adds evidence base value for money of climate change adaptation and it is also used as a forecasting tool. The CBA also supports social accountability by engaging community in a concrete way (Oxfam 2013). Furthermore, a number of econometric models have been applied for detail econometric analysis of different factors of climate change in Nepalese context. A binary probit model is effective to analyse the factors affecting farmers' decisions on adaptation to climate change. Whereas multi-nominal model is suitable for analyzing factors affecting farmers' choices of specific adaptation methods (Komba \& Muchapondwa 2015).

Yegbemey et al. (2014) also applied Heckman selection and SUR models to analyze the differential effects of farmers' behaviours such as age, gender, level of education, experience in agriculture, access to credit, membership to the organization, farm size, contact with extension and perception of adaptation to climate change. Likewise, Quang Ngo (2016) revealed that SUR Model the best option to overcome the gaps and weaknesses of univariate and multi-nominal discrete choice models. It further converges the unique maximum likelihood parameter estimates. This model is efficient than other estimation methods as it utilizes the present information in the cross-regression error correlation. Mandleni \& Anim (2011) also revealed the application of Heckman selection model to estimate the determinants of an individual farmer's decision to select adaptation.

\section{Conclusion}

Several research methodologies are available in climate change science concentrating diverse sectors (agriculture, forestry, livestock, water, health etc.) and at different levels (local to national and regional). Based on the research focuses and interests, the researchers have applied general and specific research methodologies as appropriate. Comparatively quantitative data analysis and appropriate tools and model analysis has dominated the climate change research than qualitative data. Combination of participatory research methodologies and model analysis utilizing primary and secondary sources of data is effective for the climate change research since climate change have multiple impacts at all levels. Literature review needs to be continuous throughout the research period starting from designing of the research plan to data analysis and finalization of the research outcomes.

The selection of appropriate research methodologies, methods, tools and approaches will depend on the research interests and local contexts. In Nepalese context, it is difficult to gather the climatic data because of existence of limited meteorological stations and reliable climatic data and diverse micro-climatic variations within small geographical areas. It is very crucial to carry out much of the researches on it since it has affected almost all livelihood sectors. Thus, combination of multiple research methodologies and tools including the literature review is recommended for the detail research on climate change adaptation in Nepalese context. The review and analysis of climate data and information through the use of participatory tools, econometric analysis with the use of qualitative and quantitative data are recommended in research on climate change adaptation in agriculture. 


\section{References}

Ahmed, S., Rahman, M. M., Shams, S., \& Pasha, M. M. (2014). Assessment of temporal and spatial variation of Pan Evaporation with Related climatological factors in Bangladesh. APCBEE Procedia, 10, 257-262. https://doi.org/10.1016/j.apcbee.2014.10.049

Anandhi, A. (2017). CISTA-A: Conceptual model using indicators selected by systems thinking for adaptation strategies in a changing climate: A case study in agro-ecosystems. Ecological Modelling, 345, 41-55. https://doi.org/10.1016/j.ecolmodel.2016.11.015

Andrieu, N., Sogoba, B., Zougmore, R., Howland, F., Samake, O., Bonilla-Findji, O., ... Corner-Dollof, C. (2017). Prioritizing investments for climate-smart agriculture: Lessons learned from Mali. Agricultural Systems, 154, 13-24. https://doi.org/10.1016/j.agsy.2017.02.008

Antwi-Agyei, P., Fraser, E. D. G., Dougill, A. J., Stringer, L. C., \& Simelton, E. (2012). Mapping the vulnerability of crop production to drought in Ghana using rainfall, yield and socioeconomic data. Applied Geography, 32, 324-334. https://doi.org/10.1016/j.apgeog.2011.06.010

Arshad, M., Amjath-Babu, T. S., Timothy, J. K., Aravindakshan, S., Abbas, A., Kachele, H., \& Muller, K. (2017). Climate variability and yield risk in South Asia's rice-wheat systems: Emerging evidence from Pakistan. Paddy and Water Environment, 15, 249-261. https://doi.org/10.1007/s10333-016-0544-0

Asfaw, S., McCarthy, N., Lipper, L., Arslan, A., \& Cattanco, A. (2016). What determines farmers' adaptive capacity? Empirical evidence from Malawi. Food Security, 8, 643-664. https://doi.org/10.1007/s12571-016-0571-0

Bene, C., Headey, D., Haddad, L., \& Grebmer, K. (2016). Is resilience a useful concept in the context of food security and nutrition programmes? Some conceptual and practical considerations. Food Security, 8, 123-138. https://doi.org/10.1007/s12471-015-0526-x

Berrang-Ford, L., Pearce, T., \& Ford, J. D. (2015). Systematic review approaches for climate change adaptation. Journal of Regional Environmental Change, 15, 755-769. https://doi.org/10.1007/s10113-014-0708-7

Bogale, A. (2012). Vulnerability of smallholder rural households to food insecurity in Eastern Ethiopia. Food Security, 4, 581-591. https://doi.org/10.1007/s12571.012.0208-x

Cairns, J. E., Hellin, J., Sonder, K., Araus, J. L., MacRobert, J. F., Thirfelder, C., \& Prasanna, B. M. (2013). Adapting maize production to climate change in sub-Saharan Africa. Food Security, 5, 345-360. https://doi.org/10.1007/s12571-013-0256-x

CARE (2009). Climate vulnerability and capacity assessment (CVCA): Handbook. Retrieved from www.careclimatechange.org

Cedamon, E., Nuberg, I., Pandit, B. H., \& Shrestha, K. K. (2017). Adaptation factors and futures of agroforestry systems in Nepal. Agroforestry Systems, 1-17. https://doi.org/10.1007/s10457-017-0090-9

Chagumaira, C., Rurinda, J., Nezomba, H., Mtambanengwe, F., \& Mapfumo, P. (2016). Use patterns of natural resources supporting livelihoods of smallholder communities and implications for climate change adaptation in Zimbabwe. Environment, Development \& Sustainability, 18, 237-255. https://doi.org/10.1007/s10668-015-9637-y

Chipanshi, A., Zhang, Y., Kouadio, L., Newlands, N., Davidson, A., Hill, H., ... Reichert, G. (2016). Evaluation of the Integrated Canadian Crop Yield Forecaster (ICCYF) model for in-season prediction of crop yield across the Canadian agricultural landscape. Agricultural and Forest Meteorology, 206. 137-150. https://doi.org/10.1016/j.agrformet.2015.03.007

Dawson, C. (2009). Introduction to research methods: A practical guide for anyone undertaking a research project $\left(4^{\text {th }}\right.$ Edition). Bell \& Bain Ltd, Glasgow. ISBN 9781845283674

Devkota, R. P. (2014). Climate change: Trends and people's perception in Nepal. Journal of Environmental Protection, 5, 255-265. http://dx.doi.org/10.4236/jep.2014.54029

Ebi, K. L., Padgham, J., Doumbia, M., Kergna, A., Smith, J., Butt, T., \& McCarl, B. (2011). Smallholders adaptation to climate change in Mali. Climatic Change, 108, 423-436.

https://doi.org/10.1007/s10584-011-0160-3

Environmental Protection Agency. (2016). Future climate change. Retrieved from www3.epa.gov/climatechange/science/future.html [Accessed on 8 September 2016] 
Esteve, P., Varela-Ortega, C., Blanco-Gutierrez, I., \& Downing, T. E. (2015). A hydro-economic model for the assessment of climate change impacts and adaptation in irrigated agriculture. Ecological Economics, 120, 49-58. http://dx.doi.org/10.1016/j.ecolecon.2015.09.017

Feola, G., Lemer, A. M., Jain, M., Montefrio, M. J. F., \& Nicholas, K. A. (2015). Researching farmer behaviour in climate change adaptation and sustainable agriculture: Lessons learned from five case studies. Journal of Rural Studies, 39, 74-84. https://doi.org/10.1016/j.rurstud.2015.03.009

Ghahramani, A., Kokic, P. N., Moore, A. D., Zheng, B., Chapman, S. C., Howden, M. S., \& Crimp, S. J. (2015). The value of adapting to climate change in Australian wheat farm systems: farm to cross-regional scale. Agriculture, Ecosystems and Environment, 211, 112-125. https://doi.org/10.1016/j.agee.2015.05.011

Ginkel, M., Sayer, J., Sinclair, F., Aw-Hassan, A., Bossio, D., Craufurd, P., ... Ortiz, R. (2013). An integrated agro-ecosystem and livelihood systems approach for the poor and vulnerable in dry areas. Food Security, 5, 751-767. https://doi.org/10.1007/s12571-013-0305-5

Gohar, A. A., \& Cashman, A. (2016). A methodology to assess the impact of climate variability and change on water resources, food security and economic welfare. Agricultural Systems, 147, 51-64. https://doi.org/10.1016/j.agsy.2016.05.008

Harvey, C. A., Martinez-Rodriguez, M. R., Cardenas, J. M., Avelino, J., Rapidel, B., Vignola, R., Donnati, C. I., \& Vilchez-Mendoza, S. (2017). The use of ecosystem-based adaptation practices by smallholder farmers in Central America. Agriculture, Ecosystems and Environment, 246, 279-290. https://doi.org/10.1016/j.agee.2017.04.018

Hinkel, J., \& Bisaro, A. (2015). A review and classification of analytical methods for climate change adaptation. WIREs Climate Change, 6, 171-188, https://doi.org/10.1002/wcc/322

Hussain, A., Rasul, G., Mahapatra, B., \& Tuladhar, S. (2016). Household food security in the face of climate change in Hindu-Kush Himalayan region. Food Security, 8, 921-937. https://doi.org/10.1007/s12571-016-0607-5

Islam, S., Cenacchi, N., Sulser, T. B., Gbegbelegbe, S., Hareau, G., Kleinwechter, U., ... Wiebe, K. (2016). Structural approaches to modelling the impact of climate change and adaptation technologies on crop yields and food security. Global Food Security, 10, 63-70. https://doi.org/10.1016/jgfs.2016.08.003

IUCN, IISD, SEI, Inter-cooperation. (2007). CRiSTAL - Community-based Risk Screening - Adaptation and Livelihoods: User's Manual. International Union for Nature Conservation, International Institute for Sustainable Development, Stockholm Environment Institute and Inter-cooperation

IUCN. (2015). Learning from participatory vulnerability assessments - Key to identifying EbA options. In technical paper, $21^{\text {st }}$ session of the conference of parties to the UNFCCC and $11^{\text {th }}$ session of the Conference of the Parties to the Kyoto Protocol, 30 November - 11 December. Paris. Retrieved from https://www.iucn.org/downloads/learning_from_participatory_vulnerbaility_assessment_key_to_identifying _eba_option.pdf (Accessed on 3 December 2016)

John, A., \& Fielding, M. (2014). Rice production constraints and new challenges for South Asian smallholders: Insights into de facto research priorities. Agriculture \& Food Security, 3, 18. Retrieved from http://www.agricultureandfoodsecurity.com/content/3/1/18

Karki, M., Mool, P., \& Shrestha, A. (2009). Climate change and its increasing impacts in Nepal. SUFFREC: The Initiation, 30-37

Khatri-Chhetri, A., Aggrawal, P. K., Joshi, P. K., \& Vyas, S. (2017). Farmers prioritization of climate-smart agriculture (CSA) technologies. Agricultural Systems, 151, 184-191. https://doi.org/10.1016/j.agsy.2016.10.005

Komba, C., \& Muchapondwa, E. (2015). Adaptation to climate change by smallholder farmers in Tanzania. Environment for Development. Discussion paper series. SIDA, EfD and Resources for the Future.

Lee, D. R., Edmeades, S., Nys, E. D., McDonald, A., \& Janssen, W. (2014). Developing local adaptation strategies for climate change in agriculture: A priority-setting approach with application to Latin America. Global Environmental Change, 29, 78-91. https://doi.org/10.1016/j.gloenvcha.2014.08.002

LFP. (2010). Participatory tools and techniques for assessing climate change impacts and exploring adaptation options: A community-based toolkit for practitioners. Livelihood Forestry Programme, UKaid.

Locatelli, B., Herawati, H., Brockhaus, M., Idinoba, M., \& Kanninen, M. (2008). Methods and tools for 
assessing the vulnerability of forests and people of climate change: Working Paper, Center for International Forestry Research (CIFOR). Retrieved from www.cifor.cgiar.org

Lockwood, M., Raymond, C. M., Oczkowski, E., \& Morrison, M. (2015). Measuring the dimension of adaptive capacity: A psychometric approach. Ecology and Society, 20(1), 37. https://doi.org/10.5751/ES-07203-200137

Lwasa, S. (2014). Systematic review of research on climate change adaptation policy and practice in Africa and South Asia deltas. Regional Environmental Change. https://doi.org/10.1007/s10113-014-0715-8

Mandleni, B., \& Anim, F. D. K. (2011). Climate change awareness and decision on adaptation measures by livestock farmers in South Africa. Journal of Agricultural Science. 3: 258-268. doi:10.5539/jas.v3n3p258, ISSN 1916-9752

Mechler, R., \& The Risk to Resilience Study Team. (2008). The cost-benefit analysis methodology (Risk to Resilience Working Paper No. 1). M. Moench, E. Caspari and A. Pokhrel (eds.). Kathmandu, Nepal: Institute for Social and Environmental Transition-Boulder, Institute for Social and Environmental Transition-Nepa and Provention Consortium

Mo, X., Guo, R., Liu, S., Lin, Z., \& Hu, S. (2013). Impacts of climate change on crop evapotranspiration with ensemble GCM projection in the North China Plain. Climatic Change, 120, 299-312. https://doi.org/10.1007/s10584-013-0823-3

Murage, A. W., Mildega, C. A. O., Pittchar, J. O., Pickett, J. A., \& Khan, Z. R. (2015). Determinants of adoption of climate-smart push-pull technology of enhanced food security through integrated pest management in eastern Africa. Food Security, 7, 709-724. https://doi.org/10.1007/s12571-015-0454-9

Ngeve, J. M., Jalloh, A., \& Ndjatsana, M. (2014). Review of research and policy for climate change adaptation in agriculture sector in Central Africa. Future Agricultures. Working Paper 098. Retrieved from www.future-agricultures.org

Oxfam. (2013). Applying cost benefit analysis at a community level: A review of its use for community-based climate and disaster risk management. Oxfam Research Reports. Oxfam and Tearfund. Retrieved from www.oxfam.org

Quang, N. T. (2016). Farmers' adaptive measures to climate change induced natural shocks through past climate experiences in the Mekong River Delta, Vietnam. African Journal of Agricultural Research, 11(5), 1361-1371. https://doi.org/10.5897/AjAR2015.10756, ISSN 1991-637x

Reed, M. S., Podesta, G., Fazey, I., Geeson, N., Hessel, R., Hubacek, K., ... Thomas, A. D. (2013). Combining analytical frameworks to assess livelihood vulnerability to climate change and analyse adaptation options. Ecological Economics, 94, 66-77. https://doi.org/10.1016/j.ecolecon.2013.07.007

Sacchelli, S., Fabbrizzi, S., \& Menghini, S. (2016). Climate change, wine and sustainability: A quantitative discourse analysis of the international scientific literature. Agriculture and Agricultural Science Procedia, 8 , 167-175. https://doi.org/10.1016/j.asspro.2016.02.090

Sahu, N. C., \& Mishra, D. (2013). Analysis of perception and adaptability strategies of the farmers to climate change in Odisha, India. APCBEE Procedia, 5, 123-127. https://doi.org/10.1016/j.apcbee.2013.05.022

Schut, M., Klerkx, L., Rodenburg, J., Kayeke, J., Hinnou, L. C., Raboanarielina, C. M., ... Bastiaans, L. (2015). RAAIS: Rapid Appraisal of Agricultural Innovation Systems (Part I). A diagnostic tool for integrated analysis of complex problems and innovation capacity. Agricultural Systems, 132, 1-11. https://doi.org/10.1016/j.agsy.2014.08.009

Seo, S. N. (2014). Evaluation of the Agro-Ecological Zone methods for the study of climate change with micro farming decisions in sub-Saharan Africa. European Journal of Agronomy, 52, 157-165. https://doi.org/10.1016/j.eja.2013.09.014

Sherman, M., Ford, J., Llanos-Cuentas, A., \& Valdivia, M. J. (2016). Food system vulnerability amidst the extreme 2010-2011 flooding in the Peruvian Amazon: A case study from the Ucayali region. Food Security, 8, 551-570. https://doi.org/10.1007/s12571-016-0583-9

Sterrett, C. (2011). Review of climate change adaptation practices in South Asia. Oxfam Research Reports. Retrieved from www.oxfam.org

Sud, R., Mishra, A., Varma, N., \& Bhadwal, S. (2015). Adaptation policy and practice in densely populated glacier-fed river basins of South Asia: A systematic review. Regional Environment Change, 15, 825-826, 
https://doi.org/10.1007/s10113-014-0711-z

Surendran, U., Sushanth, C. M., Mammen, G., \& Joseph, E. J. (2015). Modelling the crop water requirement using FAO-CROPWAT and assessment of water resources for sustainable water resources management: A case study in Palakkad district of humid tropical Kerala, India. Aquatic Procedia, 4, 1211-1219. https://doi.org/10.1016/j.aqpro.2015.02.154

Thierfelder, C., Mutenje, M., Mujeyi, A., \& Mupangwa, W. (2015). Where is the limit? Lessons from long-term conservation agriculture research in Zimuto Communal Area, Zimbabwe. Food Security, 7, 15-31. https://doi.org/10.1007/s12571-014-0404-y

Toda, L. L., Yokingco, J. C. E., Paringit, E. C., \& Lasco, R. D. (2017). A LiDAR-based flood modelling approach for mapping rice cultivation areas in Apalit, Pampanga. Applied Geography, 80, 34-47. https://doi.org/10.1016/j.apgeog.2016.12.020

UNFCCC. (2004). Application of methods and tools for assessing impacts, vulnerabilities, and developing adaptation responses: Background paper. FCCC/SBSTA/2004/INF.13. Bonn, Germany, Retrieved from http://unfccc.int/resource/docs/2004/sbsta/inf.13.pdf [Accessed on 14 Jan 2016]

UNFCCC. (2011). Assessing the cost and benefits of adaptation options: An overview of approaches. The Nairobi work programme on impacts, vulnerability and adaptation to climate change. United Nations Framework Convention on Climate Change. ISBN 92-9219-085-7. Retrieved from http://unfccc.int/adaptation

Uy, T. C., Limnirankul, B., \& Chaovanapoonphol, Y. (2015). Factors impacting on farmers' adaptation to drought in maize production in highland area of central Vietnam. Agriculture and Agricultural Science Procedia, 5, 75-82. https://doi.org/10.1016/j.aaspro.2015.08.011

Varadan, R. J., \& Kumar, P. (2015). Mapping agricultural vulnerability of Tamil Nadu, India to climate change: A dynamic approach to take forward the vulnerability assessment methodology. Climatic Change, 129, 159-181. https://doi.org/10.1007/s10584-015-1327-0

Wenkel, K., Berg, M., Mirschel, W., Wieland, R., Nendel, C., \& Kostner, B. (2013). LandCaRe DSS - An interactive decision support system for climate change impact assessment and the analysis of potential agricultural land use adaptation strategies. Journal of Environmental Management, 127, 168-183, https://doi.org/10.1016/j.envman.2013.02.051

Yang, L., Qin, Z., \& Tu, L. (2015). Responses of rice yields in different rice-cropping systems to climate variables in the middle and lower reaches of the Yangteze River, China. Food Security, 7, 951-963. https://doi.org/10.1007/s12571-015-0497-y

Yegbemey, R. N., Yabi, J. A., Heubach, K., Bauer, S., \& Nuppenau, E. A. (2014). Willingness to be informed and to pay for agricultural extension services in times of climate change: The case of maize farming in Northern Benin, West Africa. Climate and Development, 6(2), 132-143. https://doi.org/10.1080/17565529.2013.867249

Annex 1. Review of research and data analysis methods in climate change adaptation research

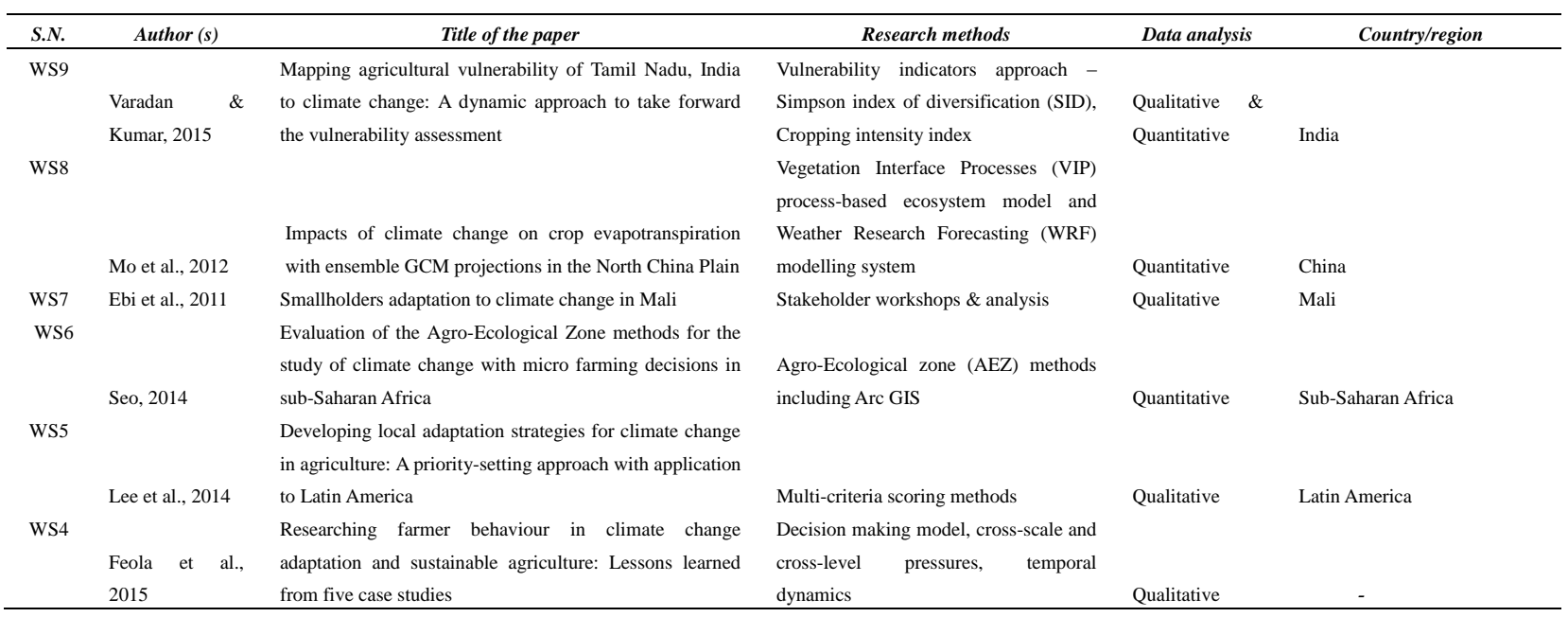




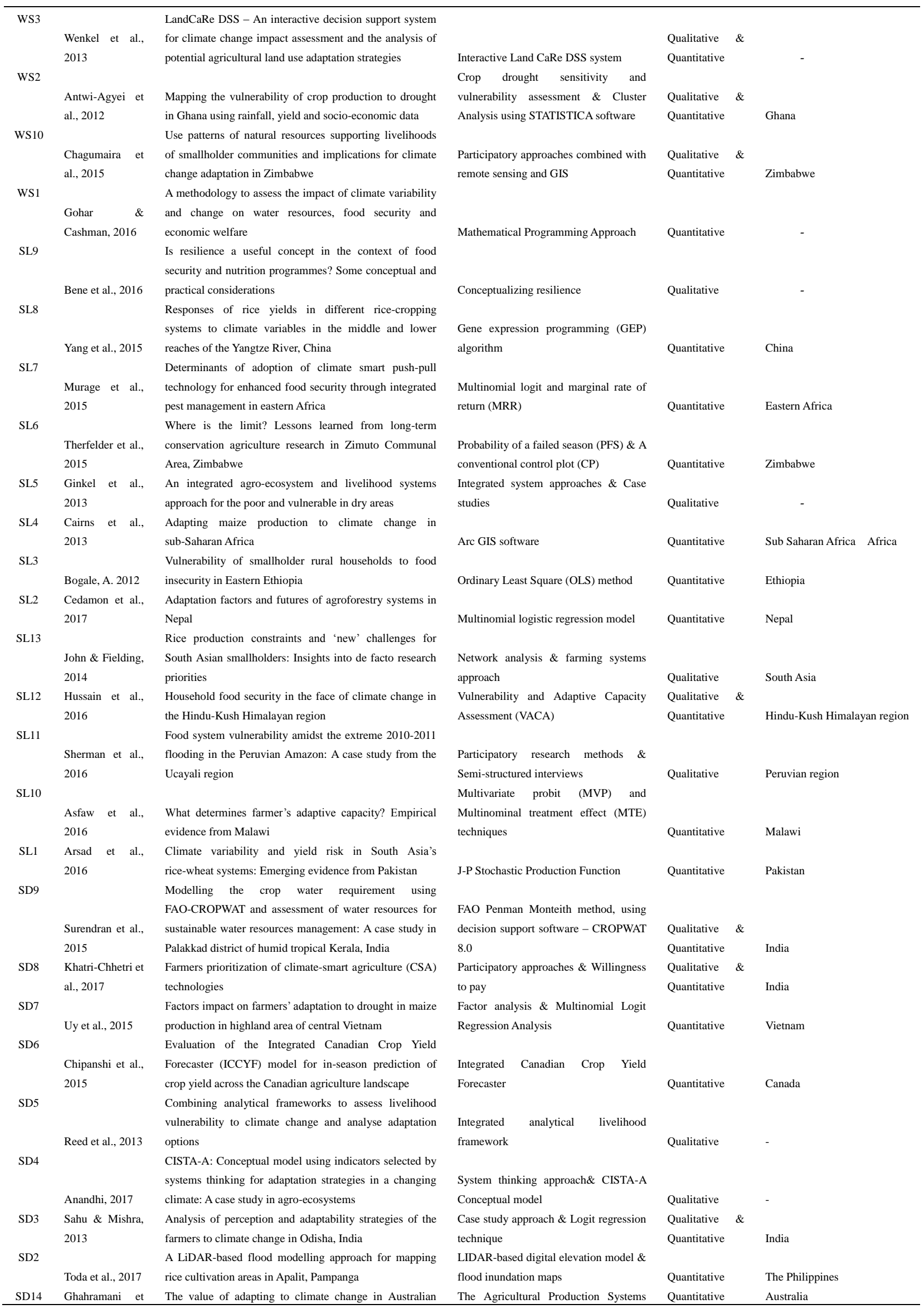




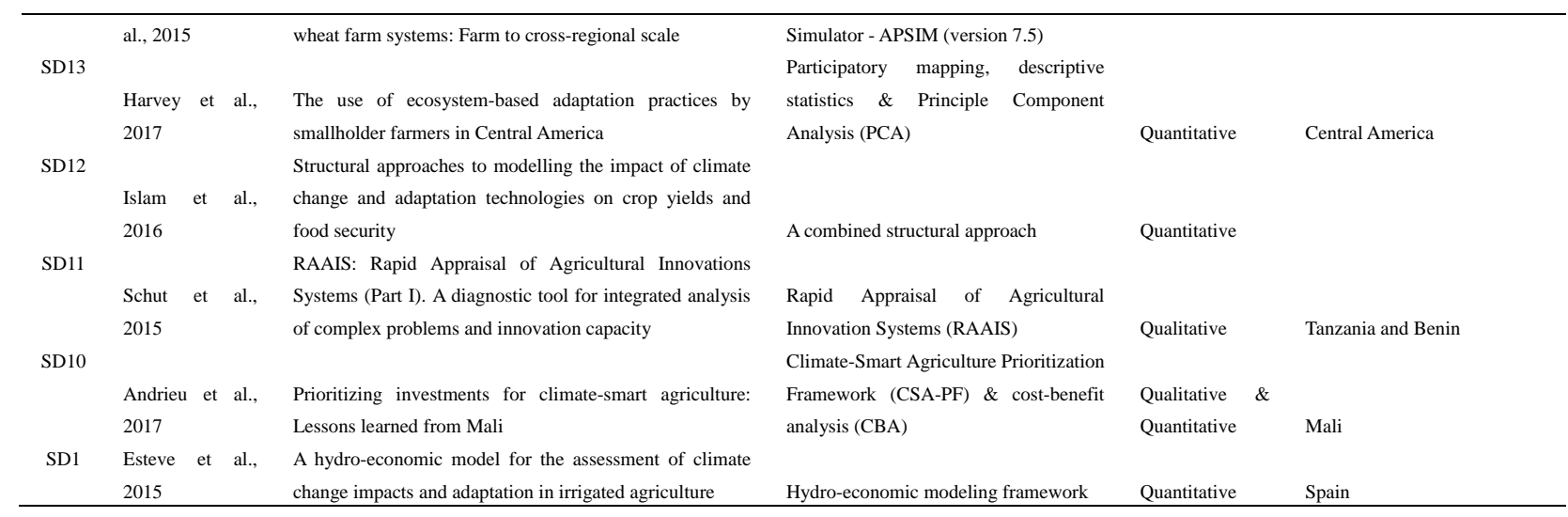

\section{Copyrights}

Copyright for this article is retained by the author(s), with first publication rights granted to the journal.

This is an open-access article distributed under the terms and conditions of the Creative Commons Attribution license (http://creativecommons.org/licenses/by/3.0/). 